\title{
ФИЛОСОФИЯ
}

\author{
УДК 1 (091)
}

\section{Проблема конфликта}

в историко-философском измерении *

\author{
С. И. Дудник, И. Д. Осипов \\ Санкт-Петербургский государственный университет, \\ Российская Федерация, 199034, Санкт-Петербург, Университетская наб., 7-9
}

Для цитирования: Дудник С. И., Осипов И. Д. Проблема конфликта в историко-философском измерении // Вестник Санкт-Петербургского университета. Философия и конфликтология. 2018. Т. 34. Вып. 2. С. 142-150. https://doi.org/10.21638/11701/spbu17.2018.201

Статья посвящена анализу проблемы конфликта в западноевропейской философии. В этой связи исследуются различные эпохи западноевропейской философии. Анализируются концепции Платона и Аристотеля и аргументируется, что античная философия конфликта была построена на синтезе мифологических и философских воззрений, которые исходили из представлений о необходимости гармонии в отношениях человека с природой и справедливости при проведении социальной политики в государстве. Исходя из этого и причины революции в обществе виделись в нарушении данного равновесия. Рассматривается и понимание конфликта в Средневековье в контексте христианской этики. Показано, что данное представление во многом определялось противопоставлением души и тела, учением о греховной природе человека. Данную философию можно определить как концепцию внутриличностных конфликтов, которая требовала выработки соответствующих медиативных практик, возникших в эту эпоху. Анализируются концепции конфликта в Новое и Новейшее время, в частности философия Локка, Канта, Милля, Гегеля и Маркса, а также конфликтология Г.Зиммеля, Л.Козера, Р.Дарендорфа. Показано, что рационалистическая философия человека и этика эгоизма во многом способствовали развитию теории личности, в которой противоречивость ее сущности рассматривается как естественное и позитивное состояние, способствующее прогрессу общества. Понятия конституционализма, демократии и правового государства отразили фундаментальные перемены в философии конфликта. На этой основе разрабатываются теоретические и практические предпосылки конфликтологии.

Ключевые слова: философия, конфликт, общество, история, личность, свобода.

* Статья написана при поддержке гранта РФФИ (ОГН) № 16-03-00623 «Отечественная философская журналистика 1917-1922 гг.».

(C) Санкт-Петербургский государственный университет, 2018 
Конфликтологическая мысль разнообразна в теоретическом и мировоззренческом отношении. Уже в далеком прошлом в мифах, религиозных и философских концепциях народов мира мы находим дуализм в понимании мироздания, борьбу сил добра и зла, света и тьмы. Победа в борьбе репрезентировала для победителей перевес добрых сил над злом и приобретала определенное сакральное и символическое значение, способствующее интеграции общества. Выделялись и отрицательные стороны конфликтного поведения: семейные и соседские ссоры, революция и гражданская война. Особенностью конфликтопонимания в эпоху Античности было синкретичное восприятие человека и общества. Оно включало совокупность мифологических, религиозных и философских представлений об обществе; в гомеровскую эпоху появляется одно из важнейших для конфликтологии понятий - агон, соперничество. Агон почитался греками как божество, а его изображение в числе других было выставлено в Олимпии в V в. до н. э. Категория агона затронула и философию, где полемика между разными школами стала важной предпосылкой развития философского знания и была связана с познанием Логоса. В лице создателя диалектики Гераклита Эфесского мы находим мыслителя, для которого бытие - становление, по его мнению, «все составилось из огня и в огонь разрешается. Все совершается по судьбе и слаживается взаимной неизбежностью» $[1$, c. 361]. В концепции государства Платона особое внимание уделено предупреждению конфликтов: для этого необходимо, чтобы каждый занимал в обществе свое место. Согласно Платону, «самое лучшее - это не война, не междоусобия: ужасно, если в них возникает нужда; мир же - это всеобщее дружелюбие» [2, с. 90]. В идеальном государстве Платона существуют элита философов и стражей, а также простой народ - крестьяне, ремесленники, торговцы. Мир обеспечивается тем, что правители и стражи лишены частной собственности и все необходимое доставляет им государство, и это предотвращает конфликты в высшем сословии. Для Платона искусство диалектики заключается в обучении человека умению мыслить, и термин «соревнование в мудрости» впервые появляется в диалоге Платона «Протагор». Спор между участниками философской беседы становится основой духовного и интеллектуального развития личности, философия позволяет преодолеть обыденные мнения, найти основу для согласия и прийти к истине. В этом контексте и агон-искусство, и спорт призваны были сыграть важную роль в гармоничном воспитании греков.

В отличие от Платона Аристотель полагал, что общество, допускающее право собственности, способно лучше сохранить свое единство. В «Риторике» он говорит и о дзелосе-соревновании: «Соревнование как ревностное желание сравниться есть нечто хорошее и бывает у людей хороших, а зависть есть нечто низкое и бывает у людей низких» [3, с. 95]. В первом случае человек под влиянием чувства стремится сам достигнуть благ, во втором - хочет, чтобы его ближний не пользовался этими благами. Склонными к соревнованию, согласно Аристотелю, будут люди, считающие себя достойными тех благ, которых они не имеют, к таковым благам относятся мужество, почет, мудрость, богатство, власть, красота, обилие друзей. По его мнению, прекрасно мстить своим врагам, так как справедливо воздавать равным за равное, мужественному человеку свойственно не допускать побед над собой. Любят также людей незлопамятных и не помнящих обид, легко идущих на примирение, ибо полагают, что по отношению к другим они будут такими же. Вражду же 
порождают гнев, оскорбление, клевета, и страшен соперник, добивающийся того же, чего добиваемся мы сами. Аристотель пишет о войне, что она нежелательна, но бывает и необходима. Чтобы вести войну, надо знать силу своего государства по мнению Аристотеля, нужно избегать столкновения с государствами более сильными или полезными для торговли. Таким образом, в античной философии анализируются различные стороны конфликтов. Умеренности, «золотой середине» соответствует политический порядок, устанавливающий равновесие и согласие между соперничающими группами общества. Эти группы зачастую вступали в полемику, что требовало соответствующей логической культуры и риторических навыков, которые вырабатывались философами.

Средневековье - период взаимодействия норм обычного права варварских народов, античного философского наследия и христианства. Предпосылки конфликтности видели в природе человеке, склонного к добру и злу. Христианство делало упор на освобождение от уз физической природы человека и развитие его духовных сил; оно с особой силой выдвигало значение свободной воли. Важнейшее место занимало учение о грехах, к которым относились убийство, воровство, чревоугодие, прелюбодеяние, уныние, гнев, зависть, гордыня, лень; сам перечень грехов церковью периодически обновлялся. Возникшее в Средневековье учение о казнях Божиих доказывало, что многое негативное в человеке следует из его греховной природы. Человек силой веры и в процессе общения с церковью может освободиться от уз греховной плоти, преодолевая конфликтность своей души. Христианство привнесло в этику новую мораль прощения своих врагов; жертвенная любовь, персонифицированная Иисусом Христом, согласно богословам, может укорениться и в обществе. В связи с этим осуждалось рабство и стала утверждаться идея морального равенства всех людей перед Богом. Однако христианство, усилив значение духовной жизни человека, в то же время по существу противопоставило ее природному бытию человека. В Новом Завете формулируется принцип повиновения верующих властям предержащим, в том числе родителям и начальникам, а Аврелий Августин в труде «О граде Божием» развивает идею правового порядка, созданного Богом для предотвращения преступлений. Следует также отметить, что средневековое общество было сословным, а потому много внимания уделялось сословному воспитанию человека. Интересна концепция естественного закона Фомы Аквинского, который он в работах «Сумма теологии» и «О правлении государей» выводит из здравого человеческого разума. Из конфликтов данного периода надо назвать борьбу католической церкви и государства за власть. Этой теме посвящена работа Данте Алигьери «Монархия», где он доказывает, что у Церкви и государства различные задачи в обществе, поэтому между ними не может быть конфликтов. Он также оправдывает право древних римлян на покорение соседних народов, отмечая, что их победа стала возможна при поддержке бога. Необходимо отметить, что Средневековье во многом было связано с конфликтами на религиозной почве, в это время были распространены преследования язычников и еретиков, велись войны между христианскими народами, устраивались крестовые походы против мусульман и славян. В связи с этим католической церковью было выработано понятие справедливых и несправедливых войн: к первым были отнесены войны между христианами и язычниками, а ко вторым - между христианскими государствами. 
В Новое время предпосылки конфликтов связывались не только с внутренним миром личности, но и с политико-правовым устройством государства. Буржуазная экономика была основана на конкуренции и представлениях о разумном индивиде, руководствующемся в жизни личной выгодой. В целом это способствовало усилению агонального характера социальных отношений, развитию принципа прав личности, свободы мысли и совести. В философии постепенно утверждается мысль о том, что все люди от природы равны, поэтому они должны иметь равные права и обязанности перед законом. Считалось также, что задача законодателя - вырабатывать законы, которые соединяют добродетель и личную выгоду. Принципиальное значение имело и то, что генезис идеи правового государства в Европе в это время был связан с войнами между протестантами и католиками. Локк в работе «Опыт о веротерпимости», определяя разумные правила отношения между государством и церковью, пишет: «...каждый человек имеет полную и неограниченную свободу мнений и вероисповедания, которой он может невозбранно пользоваться без приказа - или вопреки приказу - правителя, не зная за собой вины или греха, но всегда при условии, что делает это чистосердечно и по совести перед богом, сколько дозволяют его знания и убеждения. Однако если к тому, что он называет совестью, примешивается сколько-нибудь честолюбия, гордыни или мстительности, партийных интересов или чего-нибудь подобного, то соразмерно сему будет и его вина, и в такой мере он ответит в Судный день» [4, с. 70]. Данные положения легли в основу концепции светского государства. Религиозные войны также побудили Гроция, Локка и Канта к разработке философии международного права, к поиску «вечного мира», в котором могли бы сосуществовать различные народы. В работе «Идея всеобщей истории во всемирно-гражданском плане» Кант утверждает, что средство, которым природа пользуется для того, чтобы осуществить развитие всех задатков людей, - это антагонизм их в обществе, поскольку он, в конце концов, становится причиной их законосообразного порядка. Д.С. Милль в трактате «О свободе» большое внимание уделяет созданию условий для сочетания свободных мнений и общественного порядка. Единственная цель, ради которой общество может, по его мнению, вмешиваться в свободу действий человека, - самозащита. «Власть общества над индивидом не должна распространяться далее того, насколько действия индивидуума касаются других людей; в тех же действиях, которые касаются только его самого, индивидуум должен быть абсолютно независим над самим собою» [5, с. 296], - писал он. Порабощение личности обществом, по его мнению, может привести ко всеобщему застою. В этой связи личная свобода Миллем рассматривается в двух основных формах: внутренняя и внешняя. К внутренней свободе относится свобода совести, мысли и чувства, а внешняя включает свободу выбора образа жизни, профессии - до той поры, пока они не причиняют вреда окружающим. Философ, исходя из необходимости проведения правительством социальных реформ, допускал и расхождения между людьми, которые должны были разрешаться в ходе полемики. Он думал, что рациональные аргументы могли сблизить позиции конфликтующих сторон и привести к консенсусу.

В числе тех, кто развивал диалектическое понимание социума, необходимо назвать Гегеля. У него, как и в Античности у Гераклита, борьба получает всеобъемлющее значение. Она представляется ему необходимостью в развитии духа по направлению к свободе, элементом признания на пути совершенствования духа. 
«Совершенно в кантовском духе Гегель пишет, что после того как мы вышли из естественного состояния, оправдание насилию может служить лишь то, что оно вызвало и вызывает к “существованию”... законы, конституцию» [6, с. 84]. Гегель понимал положительное право как диалектическое развитие идеи свободы: «Идея права - свобода, и подлинного ее понимания мы достигаем лишь тогда, когда познаем ее в ее понятии и его наличном бытии» [7, с. 63]. Он связывает происхождение права с саморазвитием идеи, или мирового духа, и моментами данного развития являются общество и государственность. Диалектические законы отражают конфликтную природу свободной и разумной личности, которая должна быть понято как саморазвитие. Диалектика понимает развитие как процесс, в котором существенную роль играет внутреннее противоречие самого предмета, и оно есть та сила, которая ведет к превращению предмета в свою противоположность, определяя этим возникновение нового. Особое место в концепции Гегеля занимает война как феномен истории: «высокое значение» войны состоит в том, что она сохраняет нравственное здоровье народов, предохраняет их от гниения, которое непременно явилось бы следствием продолжительного мира. Удачные войны, по его мнению, не давали развиться внутренним смутам и укрепляли государственную власть, из войны народы выходят укрепленными, и нации, в которых существуют непримиримые антагонизмы, обретают внутреннее спокойствие.

Важнейшее значение для конфликтологии имеет философия революции Маркса и Энгельса, построенная на теории общественно-экономической формации, учении о диктатуре пролетариата и классовой борьбы, доктрине мировой революции. В классическом марксизме синтезировались ценностный подход, проявившийся в учении о диктатуре пролетариата, и научная методология, позволившая Марксу раскрыть объективные закономерности развития капитализма в XIX в., наличие превращенных форм собственности и антигуманистический характер индустриальной цивилизации. В социальной философии марксизма сохранялось подвижное равновесие между классовым и общечеловеческим, рациональным и волюнтаристским началами. Марксистская концепция человека исходит из того, что вся история есть не что иное, как постоянное преобразование природы человека. Люди, воздействуя на мир, изменяют и собственную природу. При этом «любые проблемы - как политической философии, так и философии истории - рассматривались в контексте капиталистического проекта эксплуатации человека человеком» $[8$, с. 8]. Социальная философия марксизма исходит из наличия антагонизма между классами угнетающими и угнетенными. Согласно Марксу, при капитализме возникает новый антагонизм - между производительными силами и производственными отношениями, усиливается абсолютное и относительное обнищание рабочего класса, проявляется его отчуждение от достижений культуры. Мировая коммунистическая революция начнется в наиболее развитых странах и приведет к уничтожению капитализма. Она представляет собой «самый решительный разрыв с унаследованными от прошлого отношениями собственности... она самым решительным образом порывает с идеями, унаследованными от прошлого» $[9$, с.53]. Прогресс от первобытного общества, в котором отсутствуют частная собственность и классы, к формациям, где они появляются, и далее к коммунизму возможен только в ходе классовой борьбы. И в настоящее время «капиталистической эксплуатации и дегуманизации западноевропейский марксизм 
противопоставляет возможность превращения всей социальной и культурной реальности в пространство тотального сопротивления» $[8$, с. 8].

$\mathrm{B} \mathrm{XX}$ в. развитие конфликтологии связано с работами Г.Зиммеля. На него повлияли самые разные умственные течения: дарвинизм, позитивизм, философия жизни, неоромантизм, а также концепции А.Шопенгауэра, Ф.Ницше и А.Бергсона. В работах Зиммеля рассмотрены конфликты между формами индивидуализации и социализации, в области культуры - между индивидом и культурными формами. С этой точки зрения конфликт, хотя и является одной из форм разногласия, в то же время представляет собой силу, способную объединить противоборствующие стороны, т.е. форму социализации. По Зиммелю, развитие антагонизма ведет к унификации, а единство часто становится причиной антагонизма, солидарность и враждебность не исключают друг друга. Чрезмерная близость сторон может привести к более жестоким конфликтам между ними, так как на первый план выходят малейшие различия и несогласия между сторонами. «Люди, у которых много общего, часто куда горше, несправедливее обижают друг друга, чем совершенно чуждые. Иногда это случается потому, что большая область их взаимной общности стала чем-то само собой разумеющимся, и потому не она, а то, что на данный момент их разнит, определяет позиции по отношению друг к другу» [10, с.24]. Примерами этого могут служить происходящие из-за пустяков семейные конфликты, вследствие которых расходятся вполне подходящие друг другу люди. Зиммель подчеркивает, что чем больше группы вовлечены в конфликт эмоционально, чем выше их сплоченность и чем крепче было раньше согласие между этими группами, тем острее конфликт.

Зиммель исследует и особенности централизации, которая возникает вследствие объединения против враждебной группы, и показывает, что потеря общего противника может привести к разрушению группы; чем больше острота конфликта и меньше конфликтные группы, тем выше их внутренняя сплоченность. Он доказывает, что стремление к миру - столь же естественное качество человека, как и агрессивность, и в обществе существует ритм чередования конфликтов и примирений. В целом для Зиммеля конфликт универсален, его разрешение временно, поэтому необходимо создание такого общества, в котором конфликты стали бы средством к возникновению новых форм социализации и новых культурных форм.

Социология конфликта получила дальнейшее развитие в работе Л.Козера «Функции социального конфликта». Его концепция, во многом базирующаяся на философии конфликта Зиммеля, вместе с тем придала ей социологический характер, связав с исследованием формальных сторон конфликта. Согласно Козеру, «нужно различать конфликт и враждебное, или антагонистическое, отношение. Социальный конфликт - это всегда социальное взаимодействие, тогда как отношение или чувство представляют собой только предрасположенность к действию. Предрасположенность необязательно выливается в конфликт; важнейшими промежуточными переменными, влияющими на возникновение конфликта, являются степень и способ легитимации власти и система статусов» $[11$, с.59]. В своем труде ученый детально анализирует различные виды конфликтов: внутригрупповой и межгрупповой, реалистический и нереалистический. По его мнению, социальный конфликт - это борьба за ценности и притязания на статус, власть и ресурсы, в ходе которых оппоненты нейтрализуют своих соперников, наносят им ущерб или 
устраняют их. Философа интересуют последствия социального конфликта, которые служат усилению адаптации конкретных социальных групп к тем функциям, которые выполняют не разрушительную, а положительную роль.

Одним из наиболее авторитетных представителей философии конфликта является Ральф Дарендорф, автор и редактор многих книг, в числе которых «Современный социальный конфликт. Очерки политики свободы» (1988), «Размышления о революции в Европе» (1990). Основная мысль Дарендорфа заключается в том, что современный социальный конфликт отражает антагонизм прав и их обеспечения, политики и экономики, он является конфликтом между группами удовлетворенными и требующими удовлетворения своих потребностей. При этом, по его мнению, «гетерогенное национальное государство, где люди разной культуры обладают одинаковыми основными правами, - важнейшее достижение цивилизации» $[12$, с.236]. Особое внимание в этом контексте Дарендорф уделял исследованию гражданского общества, сущность которого, по его мнению, состоит в заполнении вакуума между государственной организацией и атомизированными индивидами структурами, которые придают смысл совместной жизни людей. Оригинальность воззрений философа на гражданское общество заключается в утверждении мысли о том, что оно не обязательно является капиталистическим по структуре обеспечения права и демократическим по структуре прав. Оно возникает как «образ» сопротивления авторитарным и тоталитарным соблазнам, «без структур гражданского общества свобода остается тростинкой на ветру». В связи с этим Дарендорф развивает концепцию общественного договора, который, по его мнению, пишется заново с помощью социальных конфликтов. Суть нового общественного договора, позволяющего предотвратить революции, заключена в создании основного «состава» норм и правил, которые определяют гражданский статус личности и политическое устройство, гарантирующее ненасильственную смену власти. Строительство политических институтов ставит своей целью создание ассоциаций граждан и в перспективе - мирового гражданского общества.

Таким образом, в истоках философии конфликта находится диалектическое понимание природы человека. Стремление к социальному прогрессу, творчеству в науке и технике во многом было реализовано в современной цивилизации, и в этом состоит особая значимость конфликтологического измерения истории философии. В философии разрабатывались учения о демократии и правовом государстве, выявлялась возможность общества глубоко и объективно исследовать содержание конфликтных отношений, противостоять его негативным, разрушительным тенденциям, обращая пристальное внимание на позитивные функции социального конфликта. Становление теоретической конфликтологии дополнялось формированием все более совершенных юридических, политических и социокультурных институтов медиации, призванных разрешать социальные конфликты. Следует также учесть, что конфликтология в своем развитии исходит из конкретных социокультурных и исторических условий бытия тех или иных народов и носит историко-культурный характер. Так, отечественная интеллигенция начала XX в. «различалась в России на три главных течения в понимании права народа на революцию» [13, с.65], что во многом предопределило формирование философии революции и повлияло на социально-политические события в стране. 


\title{
Литература
} $620 \mathrm{c}$

1. Диоген Лаэртский. О жизни, учениях и изречениях знаменитых философов. М.: Мысль, 1979,

2. Платон. Соч.: в 3 т. М.: Мысль, 1972. Т. 3, ч. 2.687 с.

3. Античные риторики. М.: МГУ, 1978. 352 с.

4. Локк Д. Соч.: в 3 т. М.: Мысль, 1988. Т. 3. 668 с.

5. Милль Д. С. О свободе // Антология западноевропейской классической либеральной мысли. М.: Наука, 1995. С. 288-392.

6. Хобмайстер Х. Воля к войне, или Бессилие политики. Философско-политический трактат. СПб.: Гуманитарная Академия, 2006. 286 с.

7. Гегель Г. В. Ф. Философия права. М.: Соцэкгиз, 1934. 377 с.

8. Дудник С. И. Маркс против СССР. СПб.: Наука, 2013. 304 с.

9. Маркс К., Энгельс Ф. Манифест Коммунистической партии. М.: Прогресс, 1986. 72 с.

10. Зиммель Г. Человек как враг // Психология конфликта: Хрестоматия. 2-е изд. / под общ. ред. Н. В. Гришиной. СПб.: Питер, 2008. С. 18-25.

11. Козер Л. Функции социального конфликта. М.: Идея-Пресс, 2000. 208 с.

12. Дарендор Р. Современный социальный конфликт. Очерк политики свободы. М.: РОССПЭН, 2002. $288 \mathrm{c}$.

13. Философия русской революции: Коллективная монография / под ред. И. Д. Осипова, С. Н. Погодина. СПб.: Изд-во Политехнического университета, 2017. 188 с.

Статья поступила в редакцию 10 ноября 2017 г.; рекомендована в печать 8 февраля 2018 г.

Контактная информация:

Дудник Сергей Иванович - д-р филос. наук, проф.; s.i.dudnik@gmail.com

Осипов Игорь Дмитриевич - д-р филос. наук, проф.; idosipov@mail.ru

\section{The problem of conflict in the historical and philosophical dimension}

\author{
S. I. Dudnik, I. D. Osipov \\ St. Petersburg State University, \\ 7-9, Universitetskaya nab., St. Petersburg, 199034, Russian Federation
}

For citation: Dudnik S.I., Osipov I.D. The problem of conflict in the historical and philosophical dimension. Vestnik of Saint Petersburg University. Philosophy and Conflict Studies, 2018, vol. 34, issue 2, pp. 142-150. https://doi.org/10.21638/11701/spbu17.2018.201

The article is devoted to the issue of conflict in the history of Western philosophy. In this context, encompasses different periods in the development of Western philosophy. Analyzed concepts of Plato and Aristotle and argues that the ancient philosophy of the conflict based on a synthesis of the mythological and philosophical ideas, on ideas about the necessity of harmony in the relationship of man with nature and justice social policy in the state. The causes of the revolution in society seen in the violation of this balance. The article examines the understanding of conflicts in the Middle Ages in connection with the peculiarities of Christian ethics. It is shown that this view was mainly due to the opposition of soul and body, teaching on the sinful human nature. This philosophy can be defined as the concept of intrapersonal conflicts, which required appropriate practices to overcome conflicts. Also analyzed the concept of conflict in this New time, even in the era of modernization. In particular, analyzed the philosophy of Locke, Kant, D. S. Mill, Hegel and Marx, and the concepts of conflict G. Simmel, L. Kozer, R. Dahrendorf. It is shown that the rationalistic philosophy of man and ethics of egoism largely contributed to the development of the theory of personality in which the inconsis- 
tency of its nature is seen as natural and positive as contributing to the progress of society. The concepts of constitutionalism, democracy and the rule of law, reflected a fundamental change in the philosophy of the conflict.

Keywords: philosophy, conflict, society, history, personality, freedom.

\section{References}

1. Diogenes of Laerte. O zhizni, ucheniiakh i izrecheniiakh znamenitykh filosofov [On the life, conceptions and sayings of famous philosophers]. Moscow, Mysl', 1979. 620 p. (In Russian)

2. Plato. Sochineniia [Works], in 3 vols. Vol.3, pt. 2. Moscow, Mysl', 1972. 687 p. (In Russian)

3. Antichnye ritoriki [Antique rhetoric]. Moscow, MGU Publ., 1978. 352 p. (In Russian)

4. Lokk D. Sochineniia [Works], in 3 vols. Vol.3. Moscow, Mysl'1988. 668 p. (In Russian)

5. Mill D.S O svobode [About freedom]. Antologiia zapadnoevropeiskoi klassicheskoi liberal'noi mysli [Anthology of the West European classical liberal thought]. Moscow, Nauka Publ., 1995, pp. 288-392. (In Russian)

6. Hofmeister H. Volia $k$ voine, ili Bessilie politiki. Filosofsko-politicheskii traktat [Will to war, or the impotence of politics]. St. Peterburg, Gumanitarnaia Akademiia Publ., 2006. 286 p. (In Russian)

7. Gegel G. V.F. Filosofiia prava [Philosophy of law]. Moscow, Sotsekgiz Publ., 1934. 377 p. (In Russian)

8. Dudnik S. I. Marks protiv SSSR [Marx against the Soviet Union]. St. Petersburg, Nauka Publ., 2013. 304 p. (In Russian)

9. Marx K., Engels F. Manifest Kommunisticheskoi partii [Manifest of Communist party]. Moscow, Progress Publ., 1986. 72 p. (In Russian)

10. Zimmel G. Chelovek kak vrag [Man as an enemy]. Psikhologiia konflikta [Psychology of the conflict], $2^{\text {nd }}$ ed., under the General editorship of N.V.Grishina. St. Peterburg, Piter Publ., 2008, pp. 18-25. (In Russian)

11. Coser L. Funktsii sotsial'nogo konflikta [The Functions of social conflict]. Moscow, Ideia-Press, 2000. 208 p. (In Russian)

12. Dahrendorf R. Sovremennyi sotsial'nyi konflikt. Ocherk politiki svobody [The Modern social conflict. Essay on politics of liberty]. Moscow ROSSPEN, 2002. 288 p. (In Russian)

13. Filosofiia russkoi revoliutsii [The philosophy of the Russian revolution], Collective Monograph. Eds I. D. Osipov, S. N. Pogodin. St. Peterburg, Izdatelstvo Politechnicheskogo Universiteta. 188 p. (In Russian)

Author's information:

Sergei I. Dudnik — Dr Sci. in Philosophy, Professor; s.i.dudnik@gmail.com Igor D. Osipov — Dr. Sci. in Philosophy, Professor; idosipov@mail.ru 